\title{
MULTIVARIATE ANALYSIS OF THE BLOOD PRESSURE VARIABILITY IN BEDOUIN TRIBES OF SOUTH SINAI
}

\author{
Anna Chumakova ${ }^{1}$, Eugene Kobyliansky ${ }^{2}$ \\ ${ }^{1}$ Research Institute and Museum of Anthropology named after D.N. Anuchin, \\ M.V. Lomonosov's Moscow State University, Moscow, Russia \\ ${ }^{2}$ Department of Anatomy and Anthropology, Sackler Faculty of Medicine, \\ Tel Aviv University, Tel Aviv, Israel
}

\begin{abstract}
Objective: to study intertribal and age-related variability of blood pressure values relative to the body mass index (hereinafter - BMI) in Bedouin tribes of the South Sinai using variance analysis and canonical discriminant analysis.

Materials and methods. The samples based on physiological parameters (systolic and diastolic pressure, pulse pressure, and grip strength of the right and left hands) included 304 male and 68 female adults of Gebeliya, Muzeina, and Hamada tribes, and a combined group of representatives of various small tribes referred to as "Others". Body length, body weight, grip strength of the right and the left hands of 482 adult males and 96 adult females were studied.

Results. The studied Bedouin group, with its reduced weight and height values, stands out against the homogenous Middle East background. The performed variance analysis for the male sample revealed significant $(\mathrm{p}<0.05)$ intertribal differences in such parameters as grip strength of the right and the left hands, diastolic pressure, pulse pressure, and BMI. The increased hypertension rate was found in the age cohort of 19-29, probably due to their increased exposure to the stress associated with the ongoing social changes. According to the canonical discriminant analysis of the male sample, the Wilks' lambda value was 0.72 , and the intergroup variability was comparable to the intragroup variability.

Conclusions. The problem of obesity is non-existent in the Bedouins residing in the South of Sinai. In the South Sinai Bedouin group, no significant correlation was revealed between the blood pressure and body mass index values. This fact is accounted for by the emaciation of the population. The
\end{abstract}


authors tend to explain the low pulse pressure value in men $(39.2 \mathrm{~mm} \mathrm{Hg}$ ) by the increased peripheral vascular resistance. With the significant degree of transgression in the tribal population, the canonical discriminant analysis showed a minor incongruity in the first canonical variable. The result of the multivariate study of physiological parameters is consistent with our primary hypothesis on the ambiguity of intertribal differences in the groups living under similar environmental conditions. While not denying the existence of some individual mosaic distinctions in the Bedouin tribes, the results of the performed multivariate analysis prove the intertribal differences in the current set of physiological parameters to be insignificant.

Keywords: blood pressure, social modernization, South Sinai Bedouins, stress

The role of social environment occupies a special place among the issues concerned with the adaptation of modern human populations to various environmental factors. In particular, it is essential to identify the relation between the degree of modernization in the society and the physical status of individuals. Numerous scientific papers on the issue $(15 ; 16 ; 17 ; 25)$ focus on the risks of the onset and progression of obesity, sedentary lifestyle and the resulting hypertension, cardiovascular diseases, diabetes and other so-called "diseases of civilization."

The scientific materials collected during the expedition to South Sinai, where the Bedouin population appeared to be on the verge of modernization, provide valuable evidence regarding the physical status of a population that is the polar opposite to the population of the countries plagued with overconsumption. It should be emphasized that even 35 years after the collection of the field materials, it is evident (12) that Bedouin society has not experienced westernization yet.

Various anthropological aspects of the studied group have become the focal point of numerous scientific papers $(3,5,20,23)$. In particular, a comprehensive monograph (20) concerned with the growth and development of Bedouin children contains a detailed chapter on the history and specific features of their social relationships. Bedouins in South Sinai - are a relatively isolated group of tribes where endogamy prevails. They traditionally reside in the highlands in the south of the Sinai Peninsula. The living conditions of the South Sinai population are characterized by a lack of vital resources and health care, poor nutrition, an archaic, tribal social structure, and centuries of living in an unchangeable, severe arid mountainous semi-desert environment.

In this paper we will review the data collected by Tel Aviv University during the course of expedition to South Sinai in 1979-1982 to try to bring clar- 
ity to the previously obtained results on the physiological parameters of the Bedouin (23).

Intertribal variability of systolic (hereinafter-SBP) and diastolic (DBP) pressure in the South Sinai Bedouin population is analyzed in the work of H. Monk and joint authors (23). However, we find it unreasonable to look for the differences in the changes of blood pressure at the tribal level due to the common origin of these population groups residing in the area with a stable set of environmental conditions. In other words, it seems highly debatable that distinct differences will be found in the physiological parameters of closely related populations living in almost identical conditions. Still, a multivariate analysis is called for to verify these assumptions.

Objective. To study the intertribal and age-related variability in blood pressure values associated with the body mass index (BMI) in the Bedouin tribes of South Sinai using multivariate statistical methods.

\section{MATERIALS AND METHODS}

The anthropometric data were collected in 1979-1982 by a group of researchers from the Anatomy and Anthropology Department of the Sackler Faculty of Medicine, Tel-Aviv University (3; 20) using standard methods (22).

The BMI sample identifies 482 adult males and 96 adult females from the Gebeliya, Muzeina and Hamada tribes, and also a combined group of representatives of various small tribes referred to as Others. The blood pressure analysis includes data from 304 males and 68 females.

The BMI was calculated as the body mass $(\mathrm{kg})$ divided by the height $(\mathrm{m})$ squared.

Blood pressure was measured twice on the left arm by the same researcher (with the second measurement taken after a five-minute break), then the average of the two values was analyzed. Pulse pressure was calculated as the difference between the SBP and DBP values. The hypertension incidence rate was evaluated according to the WHO recommendations (with SBP $>140 \mathrm{~mm} \mathrm{Hg}$, and $\mathrm{DBP}>90 \mathrm{~mm} \mathrm{Hg}$ ).

All the data were analyzed in the context of the genetic variability in the Eastern Mediterranean populations.

Statistical analysis. Statistical calculations were conducted using Statistica 6 program (Statsoft Inc., 2004). To identify the genetic variability patterns of physiological parameters, multivariate methods, such as variance analysis and canonical discriminant analysis, were used. 


\section{RESULTS}

The BMI is a rough indicator poorly reflecting the true physical status of the population. However, in order to obtain imperfect but objective characteristics of fat deposition, we evaluated this factor in the Bedouin tribes sample according to the WHO ranking (32) (Table 1, Figure 1).

Table 1. Occurrence of the BMI gradations (according the WHO recommendations) in Bedouin age cohorts. Adult males

\begin{tabular}{cccc}
\hline & BMI & $\begin{array}{c}\text { Male } \\
(\mathrm{N}=484) \\
\%\end{array}$ & $\begin{array}{c}\text { Female } \\
(\mathrm{N}=96) \\
\%\end{array}$ \\
\hline underweight & $<18.50$ & 29.5 & 33.4 \\
\hline severe underweight & $<16.00$ & 1.7 & 1.0 \\
\hline moderate underweight & $16.00-16.99$ & 6.8 & 6.3 \\
\hline mild underweight & $17.00-18.49$ & 21.1 & 26.1 \\
\hline normal & $\mathbf{1 8 . 5 0 - 2 4 . 9 9}$ & 67.1 & 59.3 \\
\hline $\begin{array}{l}\text { Overweight } \\
\text { (preobesity) }\end{array}$ & $\begin{array}{c}\geq 25.00 \\
(25.00-29.99)\end{array}$ & 3.3 & 4.3 \\
\hline
\end{tabular}

graph of average and confidence intervals $(95,00 \%)$ BMI

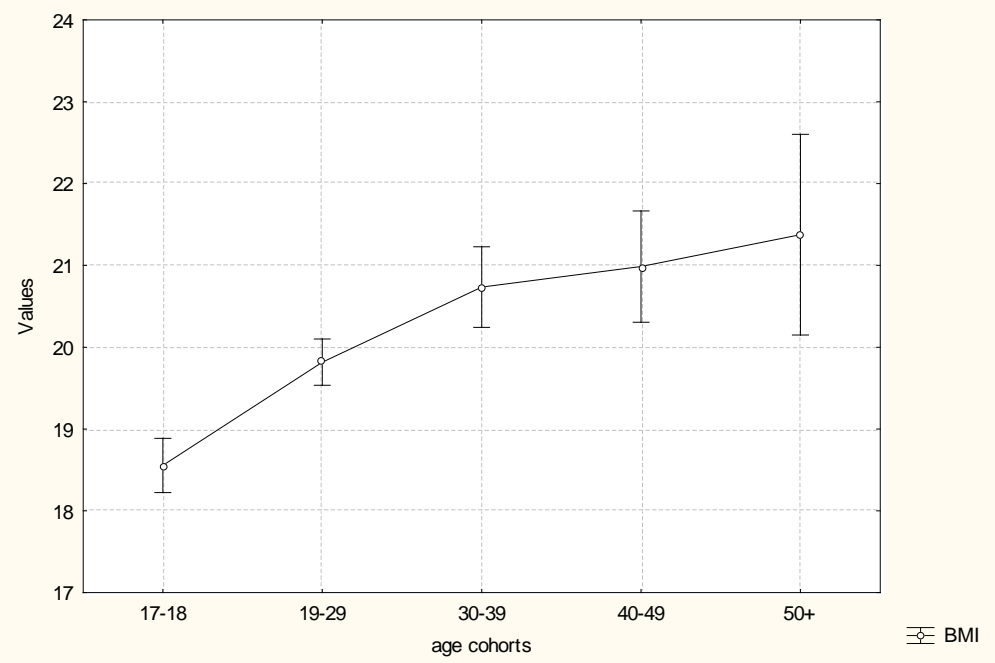

Figure 1. Mean BMI values in Bedouin age cohorts. Adult males. 
Overall, in over $40 \%$ of females and over $30 \%$ of males the BMI values were outside the normal range. Thus, this factor reduces the entire diversity of the population to the range of $15.0-27.6$, with not a single case of the BMI over 28 . The total share of the underweight population is $29.5 \%$ for males and $33.4 \%$ for females. Overweight, or, more precisely, pre-obesity is only seen in $3.3 \%$ of males and $4.3 \%$ of females in the studied population. A significant, positive correlation was established between the BMI and age ( $r=0.32$ for males, and $\mathrm{r}=0.31[\mathrm{p}<0.05]$ for females). The WHO database on the BMI for the Eastern Mediterranean region in 1980 (34) allows to compare the values of the Bedouin population with a broad variability picture of the region. It is noteworthy that the national average BMI value in Egypt for males is within the normal range while for females it slightly exceeds the norm. The Bedouin group of South Sinai populations studied in 1979-1982 stands out against the Middle East background of that period with its reduced weight and height values: the average BMI was 19.98 for males, and $20.24 \mathrm{~kg} / \mathrm{m}^{2}$ for females (Table 2).

Table 2. Mean Body Mass Index $\left(\mathrm{kg} / \mathrm{m}^{2}\right)$ in the Eastern Mediterranean region, age 20+, age standardized, 1980

\begin{tabular}{lcc}
\hline Country & BMI, males & BMI, females \\
\hline Bahrain & 23.9 & 25.2 \\
\hline Djibuti & 21.2 & 21.9 \\
\hline Egypt & 24.1 & 25.5 \\
\hline Jordan & 24.5 & 27.4 \\
\hline Kuwait & 25.5 & 28.1 \\
\hline Lebanon & 23.9 & 24.3 \\
\hline Libyan Arab Jamahiria & 24.3 & 26.8 \\
\hline Oman & 23 & 24.9 \\
\hline Qatar & 25 & 27.1 \\
\hline Saudi Arabia & 25 & 26.3 \\
\hline Syrian Arab Republic & 24.2 & 25.8 \\
\hline United Arab Emirates & 24.9 & 27.2 \\
\hline Yemen & 22.7 & 23.4 \\
\hline
\end{tabular}


Table 3 shows the hypertension incidence rate in Bedouin males.

Table 3. Incidence of elevated blood pressure in age cohorts of Bedouin men

\begin{tabular}{ccc}
\hline $\begin{array}{c}\text { Age cohorts } \\
\text { (years) }\end{array}$ & $\begin{array}{c}\text { percentage of individuals with } \\
\text { elevated }(>140 \mathrm{~mm} \mathrm{Hg}) \text { systolic } \\
\text { pressure } \\
\%\end{array}$ & $\begin{array}{c}\text { percentage of individuals with } \\
\text { elevated }\end{array}$ \\
$\begin{array}{c}>90 \mathrm{~mm} \mathrm{Hg}) \text { diastolic } \\
\text { pressure } \\
\%\end{array}$ \\
\hline $17-18$ & 0.0 & 1.95 \\
\hline $19-29$ & 4.58 & 11.40 \\
\hline $30-39$ & 2.61 & 5.54 \\
\hline $40-49$ & 1.31 & 2.93 \\
\hline $50+$ & 0.98 & 1.63 \\
\hline Total & 9.8 & 23.45 \\
\hline
\end{tabular}

The analysis of variance in the male sample revealed significant $(\mathrm{p}<0.05)$ intertribal differences in such parameters as grip strength of the right and left hands, DBP, pulse pressure, and the BMI. Figure 2 shows the variability of blood pressure in Bedouin tribes.

Giving the information of the physical status of South Sinai men grip strength indicators are rather low: the mean values for the right hand were $38.7 \mathrm{~kg}$, for left-35.7 kg. It revealed the significantly reduced grip strength of the tribe Museina's men right and left hands: $35.9 \mathrm{~kg}$ for the right hand and $31.3 \mathrm{~kg}$ for the left.. In the female sample, the grip strength of the right and the left hands (arithmetical average 25.5 and 23.11 correspondingly) was greater in the Hamada tribe compared to the Gebeliya tribe, and the BMI value of the Muzeina tribe was lower than those of the Gebeliya and Hamada tribes.

The analysis of variance performed with the male sample revealed significant age-related differences in the strength of the right and the left hands, SBP and the pulse pressure (Figure 3), and the BMI. In the female sample, the only significant differences found were those of the BMI. 


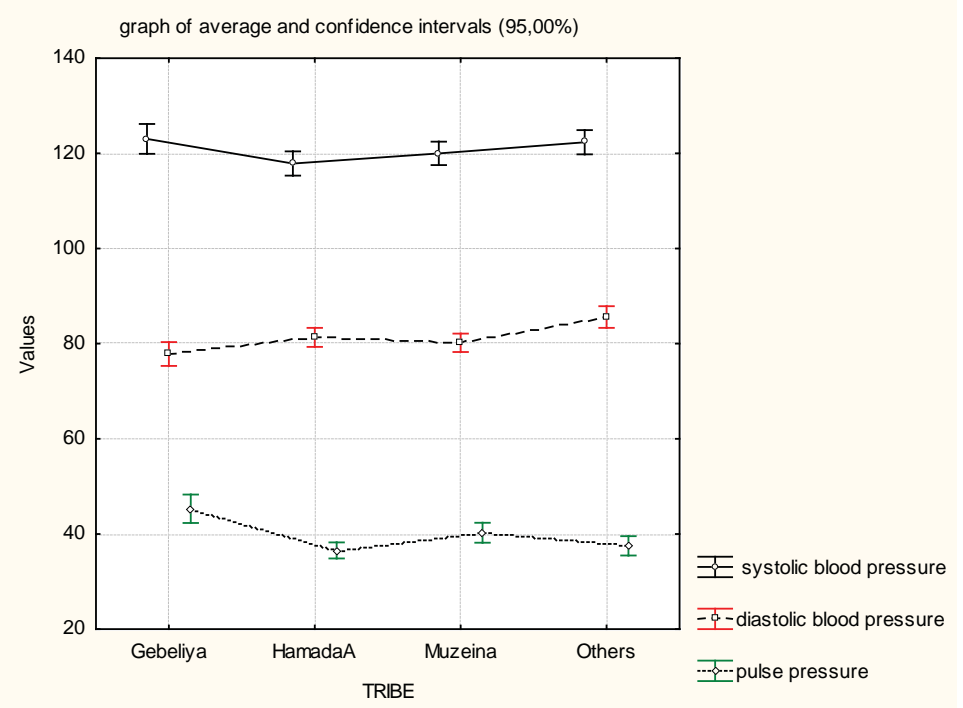

Figure 2. Intertribal variability of blood pressure. Adult males.

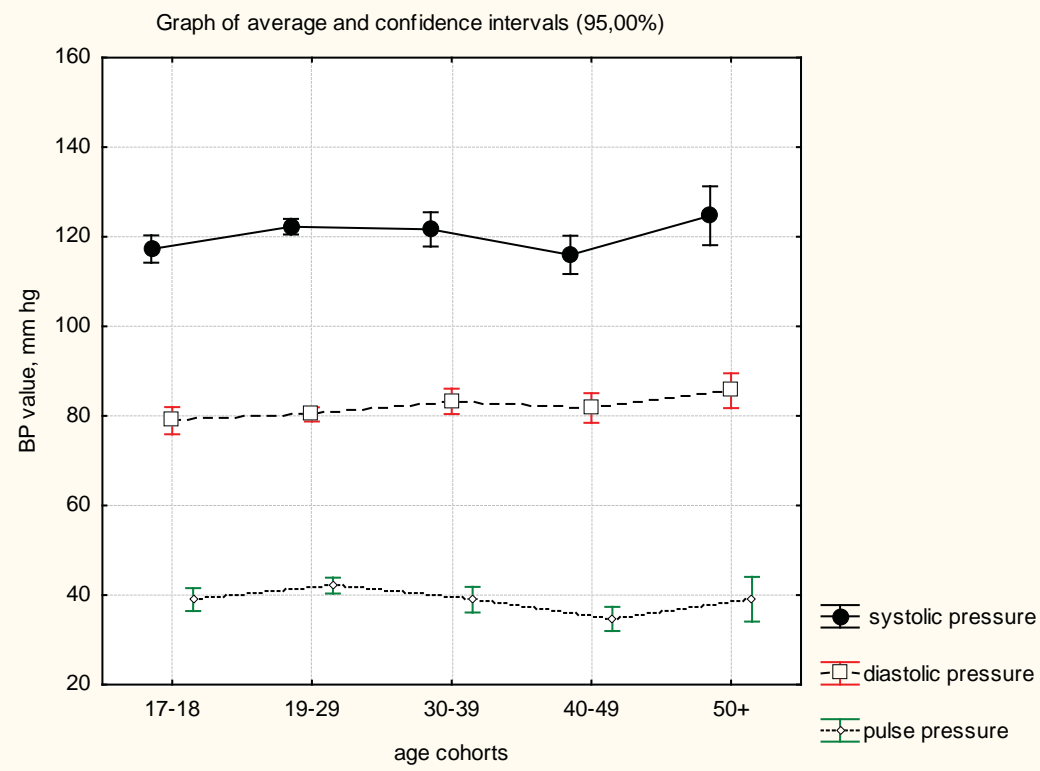

Figure 3. Age variability of blood pressure. Adult males. 
According to the diagram (Figure 4) that collates the data of the Bedouin group with the age-standardized average values of the SBP for adults (over 20 years old) in the Middle East in 1980, the Bedouin population deviates towards the lowest values of SBP. It is especially true for the low blood pressure values among Bedouin females. No significant correlation between the SBP and age was identified. The female sample revealed no significant correlation between age and blood pressure whatsoever. The Scheffe's method applied to the SBP values revealed non-random $(\mathrm{p}<0.05)$ differences between the male age cohorts of $20-39$ and $40-49$. It should be noted that the $40-49$ age cohort showed a systolic hypotension.

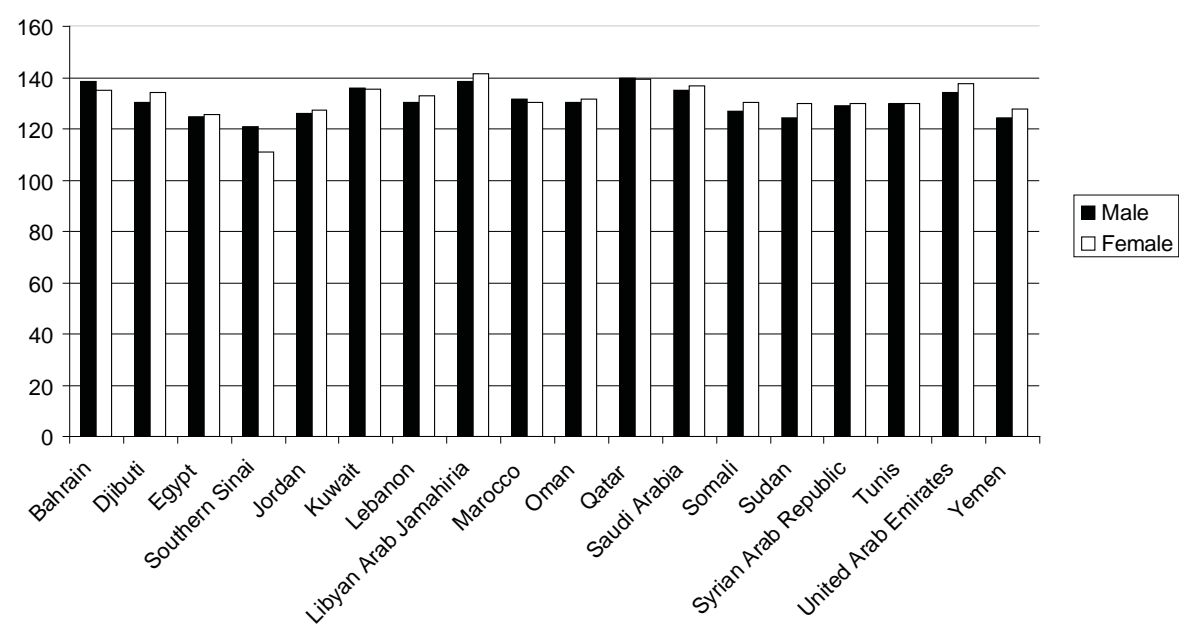

Figure 4. Systolic blood pressure variability in the Eastern Mediterranean region, 1980, age $20+$, age standardized.

According to the canonical discriminant analysis of the male sample, the Wilks' lambda value was 0.72 , thus indicating a low level of inter-tribal separation, i.e. the intergroup variability is comparable to the intragroup variability. The results of the canonical analysis are shown in Table 4. Figure 5 demonstrates the position of individuals in the range of the first two canonical variables. 
Table 4. Standardized coefficients for canonical variables

\begin{tabular}{llll}
\hline & \multicolumn{1}{c}{ Root 1 } & \multicolumn{1}{c}{ Root 2 } & \multicolumn{1}{c}{ Root 3 } \\
\hline right hand grip & 0.1228 & 0.1000 & 0.4152 \\
\hline left hand grip & 0.8833 & -0.3385 & -0.2130 \\
\hline systolic pressure & 0.2145 & -0.4247 & 1.0812 \\
\hline diastolic pressure & 0.0347 & 0.7456 & -1.5960 \\
\hline pulse pressure & -0.3248 & -0.2661 & -1.6758 \\
\hline pulse & 0.1476 & 0.3700 & -0.1541 \\
\hline BMl & -0.2154 & -0.2333 & 0.2510 \\
\hline Eigenvalues & 0.2612 & 0.0709 & 0.0264 \\
\hline Cumul. percent & 0.7285 & 0.9264 & 1.0000 \\
\hline
\end{tabular}

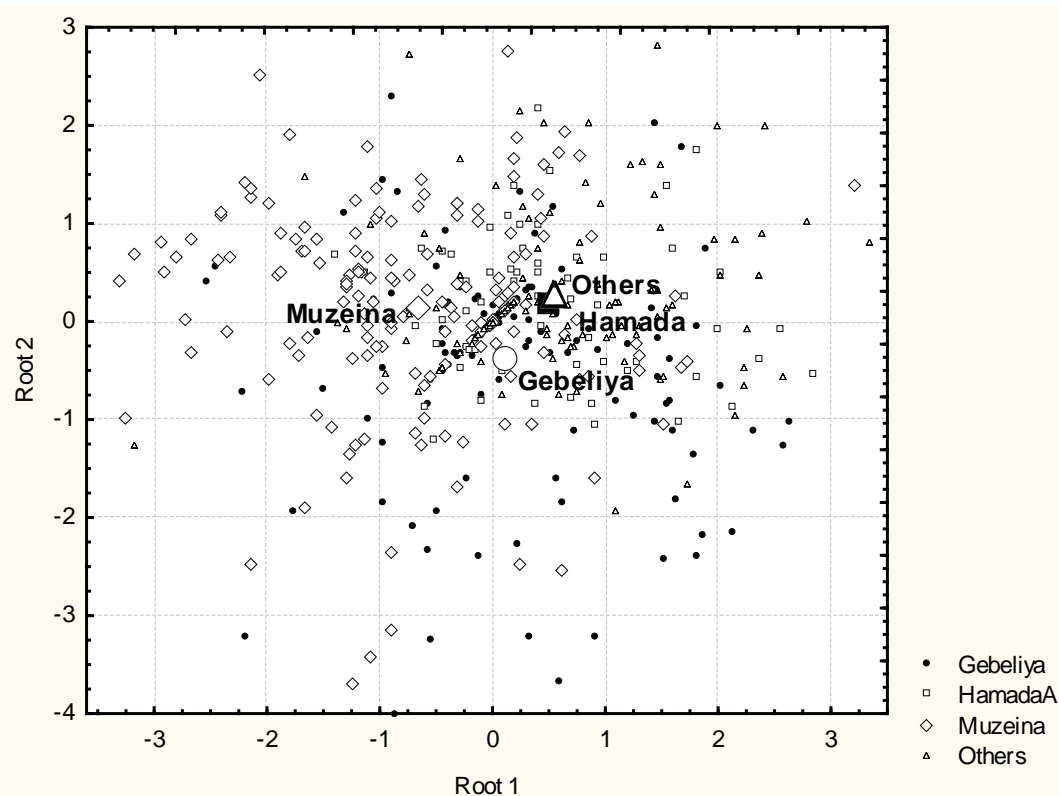

Figure 5. Results of the canonical discriminant analysi. 
The first canonical variable describes $26.1 \%$ of variability. Higher values of the first canonical variable correspond to the greater grip strength of the left hand combined with the low pulse pressure value. Negative values of the first canonical variable are seen in the individuals with the opposite combination of parameters.

The second canonical variable describes only $7 \%$ of variability. Positive values of the second canonical variable correspond to the combination of the high DBP and the low SBP pressure. Negative values of the second canonical variable correspond to the combination of the low DBP and the high SBP. The centroid of the Muzeina tribe is at the maximum distance from that of Hamada and "Other" tribes, the centroid of the Gebeliya tribe is approximately at the middle of that distance. Consequently, based on the data from Table 4, the members of the Muzeina tribe are characterized by a weaker grip strength of the left hand and a slightly elevated pulse pressure.

\section{DISCUSSION}

The obtained BMI estimates prove the claim of the inefficiency of applying the same BMI scale to different populations of the world, but still allow to evaluate the physical status of the community ranked as undernourished according to the WHO nutritional standards (11).

Our results are similar to those of the Bedouin survey in the Northern Jordan (18). The results of the BMI studies in the urban population of Palestine (1), the Negev Bedouins (13), the Saudi Arabian population $(26,28,29)$ and Jordan Bedouins (who now demonstrate a settled lifestyle (18)) showed a high rate of overweight males. Fraser et al (13) found that only 15\% of males among the Negev Bedouin in traditional nomadic groups are overweight, while in settled groups this parameter reaches 35\%. Thus, the BMI values in Bedouin tribes of South Sinai who have not embraced western lifestyle and live in a traditional stable environment differ distinctly from those of other Arab populations. According to the report presented by the World Health Organization in 2013 (35), most people residing in the Gulf countries can be regarded as the fattest people in the world; the obesity rate has also increased among the residents of other Arab countries. 35 years after the data were collected, at the beginning of the third millennium, the nomadic population of the Sinai Peninsula is still starving. This is clearly proved by the data of the joint project of the National Nutrition Institute of Egypt and the UN World Food Program conducted in the Sinai peninsula in 2005 (12). 
In the male sample of the South Sinai Bedouins, significant BMI-blood pressure correlations are low. This fact can be explained by the lack of nutritional resources that prevents gaining any excess weight and results in emaciation. In numerous studies (4, 7, 9, 10, 14, 16, 17, 31), including those of Arab populations, the excessive body weight is viewed as a risk factor for the onset of cardio-vascular diseases. The proportion of individuals predisposed to hypertension among nomadic Bedouins in the south of Sinai is significantly lower than that among Negev Bedouins (13), Palestine Arabs (1), Israeli Arabs (2), the population of Saudi Arabia $(26,28,29)$, Egypt (16,17), and Qatar (6). Nomadic and traditional communities $(15,24,27)$ report quite contradictory data on the hypertension dynamics - in some populations the incidence of hypertension does not change with age. The average incidence rate of hypertension in Bedouin tribes (23) is comparable with the rate found in non-modernized populations.

The SBP pressure is an important physiological indicator of the health status. Table 3 clearly shows an almost twofold incidence rate of elevated diastolic pressure as compared to that of the SBP pressure. The Bedouin group of South Sinai shows significant $(\mathrm{p}<0.05)$ but extremely low $(\mathrm{r}=0,14)$ correlation between diastolic pressure and age in males. W. Dressler (8) and A.I. Kozlov (21) attribute the phenomenon of elevated diastolic pressure in the population to the stress that a society experiences due to modernization. The age cohort of 19-29 shows a paradoxically high hypertension incidence rate, which can probably be accounted for by their being exposed to a greater degree of stress associated with the ongoing social changes.

The arithmetic average of pulse pressure in our male sample is $39.2 \mathrm{~mm}$ $\mathrm{Hg}$. Low $(<40 \mathrm{~mm} \mathrm{Hg}$ ) pulse pressure is known to be caused normally by an increased resistance of peripheral vessels. The southern part of the Sinai Peninsula is known for its diurnal temperature extremes; such physiological effects might be due to the prolonged exposure to cold at night (30). The analysis of age-related changes of pulse pressure in males revealed its decrease to the arithmetic average of $34.95 \mathrm{~mm} \mathrm{Hg}$ in the age cohort of 40-49 (Figure 3). In the small female sample, pulse pressure shows no distinct age dynamics. We find it difficult to explain the decrease in pulse pressure in the age cohort of 40-49-year-old Bedouins.

Given the significant degree of transgression in the tribal pool, the performed canonical discriminant analysis (Figure 5) displayed a certain incongruity by the first canonical variable. However, since the maximum distance between the centroids of the tribes by the first canonical variable composes only 1.32 of the standard deviation, and by the second canonical variable - 
only 0.64 of the standard deviation, we could not establish any significant differences in the current set of parameters. Such a result of a multivariate study of physiological parameters is consistent with our primary hypothesis on the ambiguity of intertribal differences in the groups living under similar environmental conditions. We can additionally state that, since the centroids of the Hamada and "Other" tribes are most adjacent, it would be reasonable to consider them as a single group.

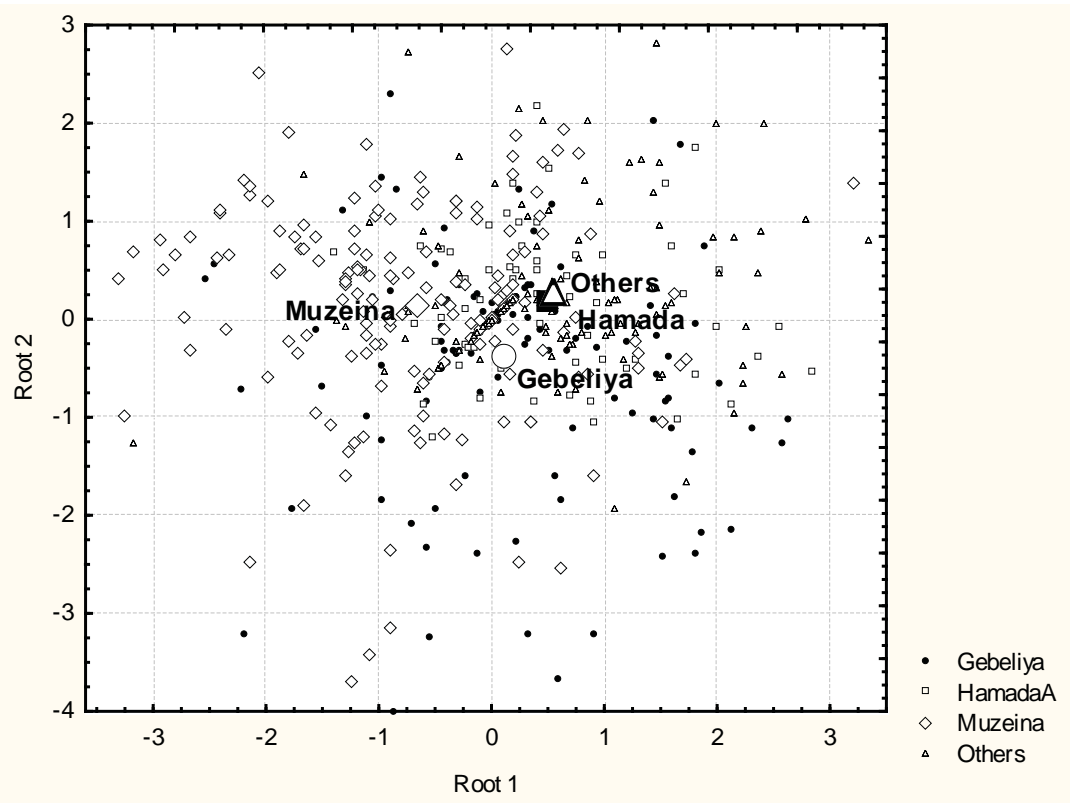

Figure 5. Results of the canonical discriminant analysis.

\section{CONCLUSIONS}

According to the materials of Tel Aviv University's expedition, the studied group of the South Sinai Bedouin populations is characterized by the lower (on the Middle Eastern scale) weight and height values. The total share of the underweight population is $29.5 \%$ for males and $33.4 \%$ for females. The problem of overweight is irrelevant for the Bedouins residing in South Sinai. The South Sinai Bedouin group showed no significant correlation between the arterial blood pressure and the BMI values. This fact is attributed to the emaciation of the population. The authors tend to explain the lower pulse pressure values in males $(39.2 \mathrm{~mm} \mathrm{Hg}$ ) by an increased peripheral cardiovascular resistance. 
While not providing the basis to deny certain individual mosaic distinctions in the Bedouin tribes, the results of the performed multivariate analysis prove the intertribal differences in the current set of physiological parameters to be insignificant.

\section{REFERENCES}

1. Abdul-Rahim H.F, Husseini A, Bjertness E, Giacaman R, Gordon NH, Jervell J. (2001). The metabolic syndrome in the West Bank population: an urban-rural comparison. Diabetes Care, Feb, 24(2), 275-9.

2. Amad S, Rosenthal T, Grossman E. (1996). The prevalence and awareness of hypertension among Israeli Arabs. J Hum Hypertens, Sep, 10 Suppl 3, S31-3.

3. Arensburg B., Hershkovitz I., Kobyliansky E., Micle S. (1979). Southern Sinai Bedouin tribes: Preliminary communication on an anthropological survey, Bull. et Mém. de la Soc. d'Anthrop. de Paris t.6, serie XIII, 363-372.

4. Banegas J.R., Fernando R., de la Cruz Troca J.J., Guallar-Castillón P., del Rey Calero J. (1998). Blood Pressure in Spain Distribution, Awareness, Control, and Benefits of a Reduction in Average Pressure. Hypertension, 32, 998-1002.

5. Belkin V., Chumakova A., Kobyliansky Eu. (2012). Physical status of the South Sinai Bedouins and particular qualities of their basal metabolism. Bulletin of Moscow University. Series 23, Anthropology, 2, 87-103.

6. Bener A., Al-Suwaidi J., Al-Jaber K, Al-Marri S., Elbagi I.E. (2004). Epidemiology of hypertension and its associated risk factors in the Qatari population. Hum Hypertens, Jul,18(7), 529-30.

7. Deshmukh PR, Gupta SS, Dongre AR, Bharambe MS, Maliye C, Kaur S, Garg BS. (2006). Relationship of anthropometric indicators with blood pressure levels in rural Wardha. Indian J Med Res, May,123(5), 657-64.

8. Dressler W. (1999). Modernization, stress, and blood pressure: New directions in research. Human Biology, 71, 4, 583-605.

9. Droyvold W.B., Midthjell K., Nilsen T.I., Holmen J.(2005). Change in body mass index and its impact on blood pressure: a prospective population study. Int J Obes (Lond), Jun, 29(6), 650-5.

10. el Mugamer I.T., Ali Zayat A.S. Hossain M.M., Pugh R.N.(1995). Diabetes, obesity and hypertension in urban and rural people of Bedouin origin in the United Arab Emirates. J. Trop. Med. Hyg, 98, 6, 407-415.

11. FAO/WHO/UNU Expert Consultation (1985). Energy and protein requirements. WHO Technical Report Series 724. Geneva, World Health Organisation, http://www.fao.org/docrep/003/aa040e/aa040e00.htm

12. Final Report Assessment of the Nutritional Statuc of Bedouins in Non-Urban Areas in Sinai. http://documents.wfp.org/stellent/groups/public/documents/ ena/wfp179696.pdf 
13. Fraser D., Weitzman S., Blondheim S., Shany S., Abou-rbiah Y. (1990). The prevalence of cardiovascular risk factors among male Bedouins: A population in transition. European J. Epidemiol, 6, 3, 273-278.

14. Gerber L.M., Stern P.M. (1999). Relationship of body size and body mass to blood pressure: sex-specific and developmental influences. Human Biology, 71, 4, 505-528.

15. Hackenberg R. A., Hackenberg B. H, Magalit H. F., Cabral E. I., Guzman S.V. (1983). Part Three: Migration, modernization and hypertension: Blood pressure levels in four Philippine communities. Medical Anthropology, CrossCultural Studies in Health and Illness, 7,1, 45-71.

16. Ibrahim M.M., Rizk H., Appel J., El-Aroussy W., Helmy S., Sharaf Y., Ashour Z., Kandil H., Roccella E., Whelton P.K. (1995). Hypertension prevalence, awareness, treatment, and control in Egypt. Hypertension, 26, 6, 886-890.

17. Ibrahim M.M., Damasceno A. (2012). Hypertension in developing countries. Lancet, Aug, 11, 380(9841), 611-9.

18. Jaddou H.Y., Bateiha A.M., Ajlouni K.M. (2000). Prevalence, awareness and management of hypertension in a recently urbanised community, eastern Jordan. Journal of Human Hypertension, 14, 8, 497-501.

19. Katz A., Biron A, Ovsyshcher E, Porath A. (2000). Seasonal variation in sudden death in the Negev desert region of Israel. Isr Med Assoc J., Jan, 2(1), 17-21.

20. Kobyliansky E., Hershkovitz I. (1997). Biology of Desert Populations - South Sinai Bedouins: Growth and Development of Children in Human Isolates. Études et Rech. Archéologiques de l'Université de Liège, Belgium, 1997, 283.

21. Kozlov A., Kozlov M., Vershubsky G., Shilov A. (2013). Health of the indigenous population of the North of Russia: on the verge of centuries and cultures. Perm.

22. Martin R. (1928). Lehrbuch der Anthropologie in systematischer Darstellung. 2 Auflage. Jena.

23. Monk-Vitelson H., Hershkovitz I. Kobyliansky E. (2001). Blood pressure variation and hypertension rates in a pre-modernized Bedouin population: data from tribes of the Sinai Peninsula (Egypt). Bulletins et mémoires de la Société d'Anthropologie de Paris, 13(3-4).

24. Pauletto P., Caroli M., Pessina A.C., Dal Palu C. (1994). Hypertension prevalence and age-related changes of blood-pressure in seminomadic and urban Oromos of Ethiopia. Eur. J. Epidemiol, 10 (2), 159-164.

25. Pereira M, Lunet N, Azevedo A, et al. (2009). Differences in prevalence, awareness, treatment and control of hypertension between developing and developed countries. J Hypertens, 27, 963-75.

26. Rahman Al-Nuaim A. (1997). High prevalence of metabolic risk factors for cardiovascular diseases among Saudi population, aged 30-64 years. Int J Cardiol, Dec 19, 62(3), 227-35. 
27. Sachdev B. (2011). Prevalence of Hypertension and associated risk among Nomad Tribe groups. Screening of Hypertension, Adiposities and ABO Blood Group among Select Nomad Tribes of Rajasthan, India. Antrocom Online J Anthropol, 7,181-9.

28. Saeed A.A., Al-Hamdan N. A., Bahnassy A.A., Abdalla A.M., Abbas M.A.F., Abuzaid L. Z. (2011). Prevalence, Awareness, Treatment, and Control of Hypertension among Saudi Adult Population: A National Survey. Int J Hypertens, 174135.

29. Soyannwo et al. (1998). Body mass index (BMI) in the Saudi population of Gassim. Afr J Med Med Sci, Mar-Jun, 27(1-2), 117-21.

30. Stocks J.M., Taylor N.A., Tipton M.J., Greenleaf J.E. (2004). Human physiological responses to cold exposure. Aviat Space Environ Med. May, 75(5), 444-57.

31. Ulijaszek S.J. (2001). Socioeconomic status, body size and physical activity of adults on Rarotonga, the Cook Islands. Ann Hum Biol.,Sep-Oct,28(5), 554-63.

32. WHO, Global Database on Body Mass Index. http://apps.who.int/bmi/index. jsp?introPage=intro_3.html

33. WHO, Overweight / Obesity: Mean body mass index trends (age-standardized estimate). Data by country. http://apps.who.int/gho/data/node.main. A904?lang=en

34. World health report 2013. http://apps.who.int/iris/bitstream/10665/85761/2/9789240690837_eng.pdf?ua=1

\section{Address for correspondence:}

Professor E. Kobyliansky

Department of Anatomy and Anthropology

Sackler Faculty of Medicine

Tel-Aviv University

Ramat-Aviv, Israel 69978

E-mail address: anatom14@post.tau.ac.il 